\title{
Erythromycin Reduces Nasal Inflammation by Inhibiting Immunoglobulin Production, Attenuating Mucus Secretion, and Modulating Cytokine Expressions: Evidence from Chronic Rhinosinusitis Model of Mice
}

\author{
Ting-Ting Yen ${ }^{1}$, Rong-San Jiang ${ }^{1}$, Ching-yun Chang ${ }^{1}$, Chih-Ying Wu ${ }^{1}$, and Kai-Li Liang ${ }^{1}$ \\ ${ }^{1}$ Taichung Veterans General Hospital
}

June 11, 2020

\begin{abstract}
Background: Allergic rhinitis (AR) and chronic rhinosinusitis (CRS) are common airway diseases worldwide. AR and CRS frequently occur together in a patient, and they share some similar pathological mechanisms. The aim of this study was to investigate the impact of AR on the pathophysiology of CRS. In addition, we explored the efficacy of erythromycin (EM) treatment on experimental CRS mice with or without AR (CRSsAR, CRSwAR). Methods: Patient nasal tissues were obtained from those underwent nasal surgery. Subjects were divided into three groups: control, CRSsAR, and CRSwAR groups. Experimental mice were divided similarly into control, CRSsAR, and CRSwAR groups. In addition, CRSsAR and CRSwAR mice were treated with EM at $0.75,7.5$, or $75 \mathrm{mg} / \mathrm{kg}$ or with dexamethasone (Dex) at $1 \mathrm{mg} / \mathrm{kg}$. Results: Allergy exacerbates nasal inflammation that was evident in nasal histology and cytokine expressions both in patients and in mice with CRS. Dex $1 \mathrm{mg} / \mathrm{kg}, \mathrm{EM} 7.5 \mathrm{or}$ $75 \mathrm{mg} / \mathrm{kg}$ treatments all effectively inhibited nasal inflammation in mice. EM reduced serum immunoglobulin levels, inhibited mucosal mucus production, and modulated local cytokine expressions in CRS mice with or without AR. Anti-inflammatory mechanisms of EM and of Dex did not appear to be the same. EM showed inhibitions on immunoglobulin production and mucus secretion stronger than Dex. Dex broadly reduced cytokine expressions whereas EM had an immunomodulatory effect on Th1/Th2 cytokine expressions. Conclusions: Comorbid AR enhanced sinonasal inflammation of CRS. EM and Dex treatments showed similar anti-inflammatory effects on CRS but through partly different mechanisms.
\end{abstract}

\section{Introduction}

Allergic rhinitis (AR) and chronic rhinosinusitis (CRS) are prevalent upper airway diseases worldwide. AR is the nasal inflammation involving immune responses of immunoglobulin $\mathrm{E}$ (IgE) and T helper (Th)-2 cells. ${ }^{1}$ CRS is defined as inflammation of sinonasal mucosa lasting $>12$ weeks. ${ }^{2}$ The pathophysiology of CRS has complex features, including anatomic variation, microbes infection, biofilm, allergy, immunodeficiencies, disturbance of epithelial barrier function, impaired mucociliary clearance, and genetic factors. ${ }^{3}$ AR and CRS are frequently found comorbid in patients and these two conditions share some similar pathological mechanisms. However, no controlled study on the impact of allergy on pathophysiology of CRS, nor well-designed study relating treatments and CRS outcomes. ${ }^{3,4}$ Recent reviews have concluded that the association between allergy and CRS remains unclear and more evidence is needed to better characterize their relationship. ${ }^{5,} 6$

Airway mucosa is the first line of defense protecting the human body from environmental pathogens, allergens, and irritants. Regarding functional airway barriers, the mucociliary escalator, epithelial integrity, and secretary antimicrobial peptides are their three primary components. ${ }^{7}$ Mucociliary clearance helps to trap invading foreign particles before removing them from the airway. Epithelial barrier is formed by epithelium, intercellular tight junction and adherens junctions. Together they maintain barrier integrity by controlling 
the paracellular permeability. Impaired mucociliary clearance is found in allergic subjects. ${ }^{8}$ Disruption of airway epithelial junctions is also a pathophysiologic finding of AR. ${ }^{9,10}$ Defects in the sinonasal epithelial barrier, increased exposures to pathogens, dysregulation of the host immune system and mucociliary clearance all of which are considered important in the pathophysiology of chronic rhinosinusitis. ${ }^{11,12}$ CRS comorbid with AR possibly further impact the nasal epithelial barrier functions.

Underlying inflammatory mechanisms are no doubt the main etiology of CRS. ${ }^{13},{ }^{14}$ Recently, researchers recommended new classification of CRS patients based on inflammatory patterns (endotype) rather than phenotypes (with or without nasal polyps). ${ }^{15}$, 16 Tomsassen et al. ${ }^{15}$ defined 10 CRS endotypes based on tissue levels of the following: interleukin (IL)-5, IL-6, IL-8, IL-17A, IL-22, IFN- $\gamma$, TNF-?, IgE, eosinophilic cationic protein, and myeloperoxidase. Bachert et al. simplified the CRS endotype classification according to Th-cell populations, Th-related cytokines and cells (non-Th-2, moderate Th-2, and severe Th-2 types). They recommended endotype-driven care pathways. ${ }^{16,17}$ Patients of CRS comorbid with allergy display immune responses comparable to those underlied by Th-2 cells. The latest published European Position Pater on Rhinosinusitis and Nasal Polyps (EPOS) 2020 recommended the simplest classification CRS patients into Th2 and non-Th2 types. ${ }^{18}$

Modalities for medical treatment of AR include oral antihistamine, nasal steroid, and leukotriene inhibitor. ${ }^{1}$ Nasal steroid and long-term macrolide are current standard treatment for CRS. ${ }^{2}$ Steroid is well-known for its broad anti-inflammatory effects whereas the macrolide effects on CRS remain unclear. The macrolide treatment originated from the dramatic life-saving outcomes on panbronchiolitis. ${ }^{19}$ Nowadays, macrolides are broadly used to treat many chronic airway diseases like CRS, cystic fibrosis, and bronchiectasis. ${ }^{20}$ Despite the widely use of macrolides in treating CRS, the EPOS 2020 recommended more studies are needed to clarify their effects. ${ }^{18}$ Mechanisms proposed on the effects of macrolides on CRS include the inhibition of biofilm formation, enhancement of mucociliary clearance, modulation of cytokines productions, and promotion of neutrophil apoptosis. ${ }^{20}$ Systematic reviews and meta-analyses reported macrolides are beneficial only on some but not all CRS patients. ${ }^{3,}{ }^{21}$ Seresirikachorn et al. ${ }^{21}$ concluded that macrolides are beneficial in treating patients with CRS without nasal polyps (CRSsNP) as opposed to CRS with nasal polyps (CRSwNP). In the study by Perić et al, ${ }^{22} \mathrm{CRSwNP}$ patients with or without AR received clarithromycin for 8 weeks. They found although cytokine levels were reduced in nasal secretion of both groups of subjects after treatment, immunomodulatory effects on cytokines were different between the two groups. The purpose of this study was to investigate the impact of AR on pathophysiology of CRS. In addition, we determined the efficacy of the erythromycin (EM), a 14-membered macrolide, on CRS mouse models with or without AR.

\section{Material and methods}

\section{Human Study}

The Research Ethic Committee of our hospital approved the present study on human subjects. Tissues were obtained from patients who had previously donated their surgical specimens to our institutional tissue bank. Nasal tissues of CRS were obtained from patients after endoscopic sinus surgery. Control tissues were from patients without rhinosinusitis but had undergone septum or turbinate surgery. The CRS diagnosis was based on typical symptoms over 12 weeks and the results of endoscopy and computed tomography (CT), in line with the criteria of EPOS 2012. ${ }^{2}$ Based on operative endoscopic findings, patients were classified as those with or without nasal polyps. All CRS patients received CT before surgery. CT images were graded according to the Lund and Mackay staging system. Findings were graded as 0, 1, or 2 with a total score range from 0 to $24 .{ }^{23}$ Patients were diagnosed with AR according to their clinical history for at least 2 years on having typical symptoms of sneezing, rhinorrhea, itchiness, and nasal obstruction when contacted with allergens and irritants. Enrolled subjects were divided into three groups: control, CRS without allergic rhinitis (CRSsAR), and CRS with allergic rhinitis (CRSwAR) groups. We did not recruit asthmatic patients in this study.

\section{Histologic Characteristics of Nasal tissues}

Tissues were fixed with buffered formalin, embedded in paraffin, and cut in slices. Hematoxylin and eosin 
(H\&E) and immunochemistry (IHC) stainings were performed to evaluate histological features, changes in protein expression at tight and adherens junctions, and mucus production. The primary antibodies for evaluating the epithelium inter-cellular junction were claudin-1 and e-cadherin (Thermo Fisher Scientific Inc., Rockford, IL, USA; GeneTex, Irvine, CA, USA). Periodic acid-Schiff (PAS) staining (ScyTek Laboratories, Inc., Logan, UT, USA) was used to evaluate mucus production. Histological slides were finally examined using a bright-field microscope, with images captured with a digital scanner, NanoZoomer 2.0 (Hamamatsu Photonics, Japan).

\section{Inflammatory Cytokines/Chemokines Expression of Nasal Tissues}

Cytokine expressions of IL-4, IL-5, IL-6, IL-10, IL-17A, and IFN- $\gamma$ in the nasal tissue homogenates (50?1, protein concentration of $5 \mathrm{mg} / \mathrm{ml}$ ) were determined using Bio-Plex ${ }^{\circledR}$.

\section{Western Blotting of Nasal Tissues}

Nasal mucosal tissues (100 mg/sample) were grained and homogenized with protein extraction buffer (Thermo Scientific, Rockford, IL, USA). Protein concentrations were measured with BCA Protein Assay (Pierce Chemical Co., Rockford, IL, USA). Equal amounts of proteins $(40 \mu \mathrm{g})$ from samples were subjected to electrophoretically separated in $10 \%$ polyacrylamide gel, transferred to polyvinylidene difluoride membrane, and then immersed in the blocking buffer for an hour at room temperature. The membrane was incubated overnight at $4^{\circ} \mathrm{C}$ with the following primary antibodies: claudin-1 (1:1000), e-cadherin (1:2000), MAC5AC (1:100), and GAPDH (1:5000) (supplied by Elabscience, Houston, USA; GeneTex, Irvine, CA, USA; abcam, Cambridge, UK, and Proteintech, Rosemont, USA). On the following day, after repeated washing, the membranes were incubated with HRP-conjugated secondary antibody and reacted at room temperature for an hour, followed by electrochemiluminescent detection (Millipore Billerica, MA, USA). The density of each protein band was scanned using ImageJ Software, version 1.46r (National Institutes of Health, Bethesda, $\mathrm{MD}$ ) and compared in densitometry.

\section{Allergic rhinitis and chronic rhinosinusitis mouse models}

The animal procedures were approved by the Institutional animal Care and Use Committee of our hospital. Female BALB/c mice at 6-8 weeks of age were obtained from the National Laboratory Animal Center in Taiwan. Sixty-one mice were divided into 3 groups: control, CRSsAR, and CRSwAR. On days 0, 7, and 14, allergic mice were sensitized each with an intraperitoneal injection of $4 \mu \mathrm{g}$ house dust mite (HDM, Indoor Biotechnologies Ltd, Cardiff, UK) mixed with $40 \mu \mathrm{g}$ aluminum hydroxide gel adjuvant (Invitrogen, San Diego, CA). From days 22 to 26 , animals received intranasal challenges with $4 \mu \mathrm{g}$ HDM. Non-allergic mice received sham sensitization (vehicle intraperitoneal injection and nasal challenges). Mice underwent nasal surgery to induce chronic rhinosinusitis. ${ }^{24}$ In brief, under anesthesia (ketamine at $100 \mathrm{mg} / \mathrm{kg}$ and xylazine hydrochloride at $10 \mathrm{mg} / \mathrm{ml}$ ), an 1-cm incision was made over the mouse head, and a $3 \mathrm{~mm}$ hole was drilled on the skull to reach nasal cavity on one side. Gelfoam pledgets (Johnson \& Johnson, Gargrave, Skipton, UK) were inserted into the nasal cavity to induce local inflammation. The scalp wounds were approximated with sutures at the end of the procedure. Mice were sacrificed on day 27. Mouse rhinosinusitis lasting $>4$ weeks was regarded, in the literature, as a chronic disease model. ${ }^{25}$ Blood samples, nasal mucosa, and nasal-associated lymphoid tissue (NALT) were collected for analyses.

Blood samples were used to measure serum levels of $\operatorname{IgE}$ and $\operatorname{IgG}$ using commercial mouse IgE and $\operatorname{IgG}$ ELISA kits according to manufacturer's instructions (BD Pharmingen, San Diego, CA, USA). Mice nasal tissue sections were examined after H\&E and IHC stainings including the following: PAS (ScyTek Laboratories, Inc., Logan, UT, USA), claudin-1 (Thermo Fisher Scientific Inc., Rockford, IL, USA) and e-cadherin (GeneTex, Irvine, CA, USA). Nasal mucosa and NALT were grinded and homogenized with the protein extraction buffer (Thermo Scientific, Waltham, MA, USA). Protein extracts from nasal mucosa were used to determine protein expressions of claudin-1, e-cadherin, MUC5AC, and GAPDH (primary antibodies supplied by Elabscience, Houston, USA; BD Pharmingen, San Diego, CA, USA; GeneTex, Irvine, CA, USA; abcam, Cambridge, UK, and Proteintech, Rosemont, USA) . Proteins extracted from NALT (50ug, concentration $1 \mathrm{mg} / \mathrm{ml}$ ) were used to determine with the Bio-Plex ${ }^{\circledR}$ (Bio-Rad, Hercules, CA, USA) local levels of cytokines 
(IL-4, IL-5, IL-6, IL-10, IL-17A, and IFN- $\gamma$ ).

Erythromycin and dexamethasone treatments on CRS mice

CRSsAR mice $(\mathrm{N}=43)$ and CRSwAR mice $(\mathrm{N}=58)$ received days 23 to 25 intraperitoneal injections of either dexamethasone $1 \mathrm{mg} / \mathrm{kg}$ (Dex) or erythromycin (EM, $0.75,7.5$, or $75 \mathrm{mg} / \mathrm{kg}$ ).

\section{Statistical Analyses}

Data were represented in frequencies or means (SEM). Chi-Square test was used to compare the categorical data. Mann-Whitney U test was used to compare continuous data between two groups. Kruskal-Wallis test was used to compare 3 or more groups. Then Dunn's multiple comparisons test was used for post hoc examination of between-group differences. Statistically significance was set at $\mathrm{P}<0.05$. Statistical analyses were performed using GraphPad Prism 6.0 (GraphPad Software, La Jolla, CA, USA) and SPSS 20.0 (SPSS, Inc, Chicago, Ill, USA).

\section{Results}

\section{Human study}

From the total of 59 enrolled patients, 12 were controls, 26 were CRSsAR, and 21were CRSwAR. The mean ages of each group were $42.08 \pm 4.34,41.62 \pm 2.34$, and $44.67 \pm 3.65$. There were 21 CRSsAR and 16 CRSwAR patients had nasal polyps. No significant differences in characteristics were found among the 3 groups, except more female patients were in the CRSwAR group $(\mathrm{P}=0.001)$. Nasal tissues from the CRSwAR group showed higher cellular infiltration and more mucus production when compared with the other two groups. In addition, in nasal epithelia of the CRSwAR group immunochemistry stainings to of claudin-1 and e-cadherin were less compared with the other two groups. Representative images of H\&E and IHC stainings are shown in Figure 1.

Protein extracts from 54 nasal tissue samples were analyzed with cytokines ELISA testing and 50s samples analyzed with western blotting. Cytokines levels of IL-4, IL-5, IL-10, and IL-17A in tissue homogenates from patients with CRSwAR were significantly higher than those of controls $(\mathrm{P}=0.0027,0.0004,0.0015$, and 0.0205, respectively). In addition, IFN- $\gamma$ levels were significantly higher in both CRSsAR and CRSwAR than controls (CRSsAR vs. control: $\mathrm{P}=0.0474$; $\mathrm{CRSwAR}$ vs. control, $\mathrm{P}=0.0005$ ) (Figure $2 \mathrm{~A}$ ). Western blotting showed a protein expression tendency of increasing MUC5AC and decreasing e-cadherin and claudin-1 in nasal mucosa from CRS patients when compared with controls (Figure 2B\&C). Nevertheless, the apparent differences were not statistically significant between groups (MUC5AC, e-cadherin, claudin-1, $\mathrm{P}=0.1899$, 0.3014 , and 0.8877 , respectively).

\section{Mice models of rhinosinusitis with or without allergy}

AR mice showed significantly higher levels of total and HDM-specific IgE when compared with the non-AR mice (control vs. CRSwAR, CRSsAR vs. CRSwAR, both P <0.0001). CRSsAR mice had significantly higher serum IgG2a levels compared with controls or CRSwAR mice (control vs. CRSsAR, P =0.018, and CRSsAR vs. CRSwAR, P <0.0001) (Figure 3). In nasal epithelia of diseased mice, H\&E staining showed greater mucosal cellular infiltration, lower epithelial IHC stainings for claudin-1 and e-cadherin, and higher PAS staining. (Figure $4 \mathrm{~A} \& \mathrm{~B}$ ).

Allergic mice had significantly higher levels of IL-4 and IL-5 levels in tissue homogenates from NALT compared with controls (IL4: CRSwAR vs. control, P $=0.0024$, CRSwAR vs. CRSsAR, P =0.0384; IL5: CRSwAR vs. control, $\mathrm{P}=0.0279$ ) (Figure 5). MUC5AC protein expression appeared higher in nasal tissues of the CRSsAR or CRSwAR mice than that of controls. The difference between CRSwAR and controls was statistically significant (CRSwAR vs. Control, $\mathrm{P}=0.0144$ ). There was a tendency of decreased e-cadherin protein expression in rhinosinusitis mice with or without AR (Figure 6).

Effect of Erythromycin or dexamethasone treatment on experimental mice 
CRSwAR mice treated with $7.5 \mathrm{mg} / \mathrm{kg}$ EM or $1 \mathrm{mg} / \mathrm{kg}$ Dex significantly lowered their serum levels of total IgE when compared with the untreated CRSwAR mice $(\mathrm{P}=0.0142$ and $=0.0434$, respectively). CRSsAR mice had significantly lower serum levels of IgG2a after treatment with 7.5 or $75 \mathrm{mg} / \mathrm{kg}$ EM (both $\mathrm{P}<0.0001$ ) or after $1 \mathrm{mg} / \mathrm{kg}$ Dex $(\mathrm{P}=0.023)$ when compared with untreated mice. CRSwAR mice treated with 75 $\mathrm{mg} / \mathrm{kg}$ EM also significantly lowered their IgG2a levels when compared with untreated mice $(\mathrm{P}=0.0274)$. In addition, 7.5 and $75 \mathrm{mg} / \mathrm{kg}$ EM-treated CRSwAR mice showed significantly lower serum levels of IgG2a compared with Dex-treated CRSwAR mice ( $\mathrm{P}=0.0168$ and $=0.0075$, respectively) (Figure 3 ).

After treatments with 7.5 or $75 \mathrm{mg} / \mathrm{kg} \mathrm{EM}$, or with Dex, we found reduced cellular infiltrations in nasal histology of CRS mice (with or without AR). Marked reduction in mucus production was especially noted in CRS mice receiving EM treatments. In addition, we found stronger e-cadherin stainings in nasal tissues of EM-treated mice when compared with untreated mice (Figure $4 \mathrm{~A} \& \mathrm{~B}$ ).

Cytokine expressions in NALT homogenates demonstrated an immunomodulation effect of EM (Figure 5). CRSsAR mice treated with $7.5 \mathrm{mg} / \mathrm{kg}$ EM had significantly elevated IL-10 levels in NALT homogenates than untreated CRSsAR mice $(\mathrm{P}=0.038)$. In addition, EM-treated mice had significantly higher IL-10 levels than Dex-treated mice (CRSsAR: EM $7.5 \mathrm{mg} / \mathrm{kg}$ vs. Dex, $\mathrm{P}=0.0021$; EM $75 \mathrm{mg} / \mathrm{kg}$ vs. Dex, P $=0.0419$; CRSwAR: EM $7.5 \mathrm{mg} / \mathrm{kg}$ vs. Dex, $\mathrm{P}=0.0044$; EM $75 \mathrm{mg} / \mathrm{kg}$ vs. Dex, $\mathrm{P}=0.0071)$. Interestingly, a reversal of Th-1/Th-2 cytokine expressions was found in the EM-treated mice. NALT IL-5 levels increased in the 7.5 and $75 \mathrm{mg} / \mathrm{kg}$ EM-treated CRSsAR mice, and both were significantly higher than the Dex-treated mice ( $\mathrm{P}=0.0397$, and 0.0358 , respectively). In the CRSwAR group, NALT IL- 6 and IFN- $\gamma$ levels significantly rose in the $7.5 \mathrm{mg} / \mathrm{kg}$ EM-treated than the untreated mice, as well as the Dex-treated mice (IL-6: EM 7.5 $\mathrm{mg} / \mathrm{kg}$ vs. untreated, $\mathrm{P}=0.0473, \mathrm{EM} 7.5 \mathrm{mg} / \mathrm{kg}$ vs. Dex, $\mathrm{P}=0.0028 ; \mathrm{IFN}-\gamma: \mathrm{EM} 7.5 \mathrm{mg} / \mathrm{kg}$ vs. untreated, $\mathrm{P}=0.0282$, EM $7.5 \mathrm{mg} / \mathrm{kg}$ vs. Dex, $\mathrm{P}=0.0002)$. Regarding IL-17A, levels were significantly higher in NALT of the 7.5 and $75 \mathrm{mg} / \mathrm{kg}$ EM-treated CRSwAR mice than the Dex-treated mice $(\mathrm{P}=0.007$ and $=0.0378$, respectively).

MUC5AC protein expressions were significantly reduced in the 7.5 or $75 \mathrm{mg} / \mathrm{kg}$ EM-treated CRSsAR mice compared with untreated mice $(\mathrm{P}=0.0003$ and $=0.0032$, respectively). Similarly, CRSwAR mice receiving 7.5 or $75 \mathrm{mg} / \mathrm{kg}$ EM treatment had significantly lower MUC5AC protein expressions in nasal tissue when compared with untreated mice $(\mathrm{P}<0.0001$ and $=0.0135$, respectively $)$. In addition, we found significant differences in MUC5AC protein expressions between $7.5 \mathrm{mg} / \mathrm{kg}$ EM-treated and Dex-treated CRSwAR mice $(\mathrm{P}=0.0191)$. For tight or adherence protein expressions, both CRSsAR and CRSwAR mice showed higher e-cadherin expressions in nasal tissues after treatments with 7.5 or $75 \mathrm{mg} / \mathrm{kg}$ EM. No significant difference was found between EM-treated and untreated groups, but EM-treated CRS mice had significantly higher e-cadherin expression than Dex-treated mice (CRSsAR: EM $75 \mathrm{mg} / \mathrm{kg}$ vs. Dex, P =0.0294; CRSwAR, EM $75 \mathrm{mg} / \mathrm{kg}$ vs. Dex, $\mathrm{P}=0.0105$ ) (Figure 6).

\section{Discussions}

Our CRS subjects, with or without AR, showed similar CT grading scores and incidence of polyposis. Nevertheless, CRSwAR patients showed in their nasal tissues, signs of stronger mucosal inflammation, higher mucus production, higher Th-2 cytokines expression, and poorer barrier integrity when compared with those without AR. Similar phenomena were observed in our experimental mice. Our results supported that allergy exacerbates sinonasal inflammation in rhinosinusitis. Xing et al. ${ }^{26}$ conducted a study investigating the effect of AR on nasal mucosa remodeling with nasal tissues taken from CRSsAR and CRSwAR patients. They concluded that AR could enhances tissue remodeling process in CRS. Furthermore, our results are consistent with CRS endotype being a better predictor than phenotype on disease severity. Based on the underlying inflammatory patterns, the classification of CRS patients with endotype could choose precise therapeutic strategy better for patients, and hence a better prediction of treatment outcome. ${ }^{27}$

In our current study, we found that both EM and Dex effectively reduced serum levels of IgE in allergic mice. Furthermore, EM and Dex treatments both reduced serum IgG2a production in either CRSsAR and CRSwAR mice. But the inhibition effect on IgG2a production was stronger in the EM than the Dex 
treatment. Shamji et al. ${ }^{28}$ studied local IgE and IgG levels in nasal tissue homogenates taken from CRSwNP patients, and they suggested that IgE/IgG interaction plays a role in controlling local inflammation in the nasal polyps. Only two randomized controlled studies have so far been conducted relating macrolides treatment on CRS patients measuring IgE levels at the time of enrollment: Wallwork et al. ${ }^{29}$ reported that macrolides have benefits especially on CRS patients with low levels of IgE, but Hexel at al. ${ }^{30}$ did not found such advantage in their similar patients. Consistent with our present results, macrolides could have a role in treating IgE-medicated allergic airway diseases despite reported studies favored benefits on low-IgE CRS subjects.

Mucociliary clearance and epithelial barrier integrity play important roles in protecting airways from foreign invaders. We had conducted a randomized, active comparator-controlled study comparing the effects of intranasal steroid or low dose EM towards patients with refractory rhinosinusitis after surgery. ${ }^{31}$ Results of aforementioned study demonstrated that naso-endoscopic scores improved after intranasal steroid or EM treatment, but the improvement in mucociliary function (saccharide transit time) was significantly higher in the EM group than in the intranasal steroid group (improvement rate: $64.9 \%$ vs. $35.1 \%$ ). In current study, EM-treated CRS mice significantly reduced mucin protein expressions than untreated mice. Of note, reduction of mucus production after treatment of EM was significantly stronger than Dex. Disruption of epithelial barrier junction can enhance the infiltration of pathogens or allergens into the submucosal area, stimulating airway inflammation. ${ }^{9}$ Soyka et al. reported the phenomena of lowered tight junction protein expressions in the epithelia of sinonasal tissues taken from patients with CRS. ${ }^{32}$ In our current study, we found that epithelial barrier function was poorer in CRS subjects and experimental CRS mice. Miyagawa et al. reported that azithromycin recovers the reduced e-cadherin expressions in human gingival epithelial cells when stimulated with tumor necrotic factor-alpha. ${ }^{33}$ However, the effect of EM on restoring nasal epithelial barrier dysfunction was not studied in our patients.

Cytokines and chemokines are key regulators of the inflammatory responses. Previous studies of macrolides on CRS patients revealed no consistent effects on cytokine productions. For example, some reported that macrolides inhibit the release of IL-8, a potent neutrophil chemoattractant. Wallwork et al. ${ }^{29}$ conducted a randomized, placebo-controlled trial of roxithromycin on CRS patients and found a reduction of IL-8 in nasal lavage after roxithromycin treatment. Macrolides are also known to affect allergic asthma with their steroid-spare effects on cytokine expressions. ${ }^{34}$ Sadamatsu et al. ${ }^{35}$ treated asthmatic mice with a nonantibiotic macrolide EM900 and found significantly lower levels of IL-5, IL-13, RANDTES, and IL-17A in their bronchoalveolar lavage. Pukhyalsky et al. ${ }^{36}$ studied patients with cystic fibrosis, their cytokines changes in peripheral blood and sputum after prolonged treatments of clarithromycin. They found significant improvements of lung function and a switch from Th-2 to Th-1 cytokines in their blood and sputum. Interestingly, Park et al. ${ }^{37}$ found in patients with panbronchiolitis, a shift from Th-1 to Th-2 cytokine production in bronchoalveolar lavage fluid after long-term treatment with EM. The Th-1/Th-2 cytokines switches observed in the two human studies could reflect an immune-modulatory effect of macrolides. We found that IL-10 was elevated in both our CRSsAR and CRSwAR EM-treated mice. Th-2 cytokine levels were increased in EM-treated CRSsAR mice whereas Th-1 cytokine levels were elevated in the EM-treated CRSwAR mice.

Clinical studies of macrolides on CRS involved application of various drugs and at different dosages. But the optimal drug, dosage, or duration are not currently known. Subgroup analyses of Seresirikachorn's metaanalysis showed the results favor patients receiving a half dose macrolide compared to a very low doses, and favor macrolide treatment for a duration of 24 weeks instead of shorter periods. ${ }^{8}$ In our current study, we found that medium and high doses $(7.5$ and $75 \mathrm{mg} / \mathrm{kg}$ ) worked well for treating of CRS. No dose-response could be with only 3 doses were used in our study. A recent meta-analysis reported that adding a macrolide to an intranasal steroid may achieve better results than using steroid alone to treat CRS. ${ }^{38}$ Our mice experiments showed Dex and EM treatments effects on CRS acted through somewhat different mechanisms. Combining of two drugs is likely a choice of treatment for patients unresponsive to monotherapy.

There are some limitations in this current study. First, we did not collect nasal tissues from our patients 
receiving EM or Dex treatment. Second, CRS patients comorbid with asthma whose disease burden is typically higher than the non-asthmatics, were not enrolled in our study. Third, we did not evaluate the effects of combined treatment of EM and Dex. Further in-depth studies on dose escalation and mechanisms of macrolide treatment may help to establish optimal CRS therapeutic strategies for clinical use.

\section{Conclusion}

In our current study, we identified that comorbid AR exacerbates CRS severity. Erythromycin effects on CRS by reducing immunoglobulins production, inhibiting mucin secretion, and modulating cytokines expression. The mechanisms of erythromycin and steroid treatment on CRS are different. Combined two drugs could be considered for patients unresponsive to monotherapy.

\section{Authorship contribution}

TTY and RSJ drafted the manuscript. CYC and CYW performed experiments and data collection. KLL contributed to study design, data collection, and manuscript drafting.

\section{Conflict of interest}

The authors declare no conflict of interest.

\section{Reference List}

1. Bousquet J, Khaltaev N, Cruz AA, et al. Allergic Rhinitis and its Impact on Asthma (ARIA) 2008 update (in collaboration with the World Health Organization, GA(2)LEN and AllerGen). Allergy . 2008; 63 Suppl $86: 8-160$.

2. Fokkens WJ, Lund VJ, Mullol J, Bachert C, Alobid I, Baroody F, et al. European Position Paper on Rhinosinusitis and Nasal Polyps 2012.Rhinol Suppl. 2012(23):3 p preceding table of contents, 1-298.

3. Orlandi RR, Kingdom TT, Hwang PH, Smith TL, Alt JA, Baroody FM, et al. International Consensus Statement on Allergy and Rhinology: Rhinosinusitis. Int Forum Allergy Rhinol. 2016; 6 Suppl 1:S22-209.

4. Kariyawasam HH, Rotiroti G. Allergic rhinitis, chronic rhinosinusitis and asthma: unravelling a complex relationship. Curr Opin Otolaryngol Head Neck Surg. 2013; 21(1):79-86.

5. Helman SN, Barrow E, Edwards T, DelGaudio JM, Levy JM, Wise SK. The Role of Allergic Rhinitis in Chronic Rhinosinusitis. Immunol Allergy Clin North Am . 2020; 40(2):201-214.

6. Wilson KF, McMains KC, Orlandi RR. The association between allergy and chronic rhinosinusitis with and without nasal polyps: an evidence-based review with recommendations. Int Forum Allergy Rhinol. 2014; 4(2):93-103.

7. Ganesan S, Comstock AT, Sajjan US. Barrier function of airway tract epithelium. Tissue Barriers . 2013; 1(4):e24997.

8. Alho OP. Nasal airflow, mucociliary clearance, and sinus functioning during viral colds: effects of allergic rhinitis and susceptibility to recurrent sinusitis. Am J Rhinol. 2004; 18(6):349-355.

9. Fukuoka A, Yoshimoto T. Barrier dysfunction in the nasal allergy.Allergol Int. 2018; 67(1):18-23.

10. Steelant B, Farre R, Wawrzyniak P, et al. Impaired barrier function in patients with house dust miteinduced allergic rhinitis is accompanied by decreased occludin and zonula occludens- 1 expression.J Allergy Clin Immunol. 2016; 137(4):1043-1053 e1045.

11. Antunes MB, Gudis DA, Cohen NA. Epithelium, cilia, and mucus: their importance in chronic rhinosinusitis. Immunol Allergy Clin North Am . 2009; 29(4):631-643.

12. Stevens WW, Schleimer RP, Kern RC. Chronic Rhinosinusitis with Nasal Polyps. J Allergy Clin Immunol Pract. 2016; 4(4):565-572. 
13. Stevens WW, Lee RJ, Schleimer RP, Cohen NA. Chronic rhinosinusitis pathogenesis. J Allergy Clin Immunol. 2015; 136(6):1442-1453.

14. Van Crombruggen K, Zhang N, Gevaert P, Tomassen P, Bachert C. Pathogenesis of chronic rhinosinusitis: inflammation. J Allergy Clin Immunol. 2011; 128(4):728-732.

15. Tomassen P, Vandeplas G, Van Zele T, et al. Inflammatory endotypes of chronic rhinosinusitis based on cluster analysis of biomarkers.J Allergy Clin Immunol. 2016; 137(5):1449-1456 e1444.

16. Bachert C, Akdis CA. Phenotypes and Emerging Endotypes of Chronic Rhinosinusitis. J Allergy Clin Immunol Pract. 2016; 4(4):621-628.

17. Bachert C, Zhang N, Hellings PW, Bousquet J. Endotype-driven care pathways in patients with chronic rhinosinusitis. J Allergy Clin Immunol. 2018; 141(5):1543-1551.

18. Fokkens WJ, Lund VJ, Hopkins C, et al. European Position Paper on Rhinosinusitis and Nasal Polyps 2020. Rhinology. 2020; 58(Suppl S29):1-464.

19. Lin X, Lu J, Yang M, Dong BR, Wu HM. Macrolides for diffuse panbronchiolitis. Cochrane Database Syst Rev. 2015; 1:CD007716.

20. Kanoh S, Rubin BK. Mechanisms of action and clinical application of macrolides as immunomodulatory medications. Clin Microbiol Rev.2010; 23(3):590-615.

21. Seresirikachorn K, Suwanparin N, Srisunthornphanich C, Chitsuthipakorn W, Kanjanawasee D, Snidvongs K. Factors of success of low-dose macrolides in chronic sinusitis: Systematic review and meta-analysis. Laryngoscope. 2019; 129(7):1510-1519.

22. Perić A, Vojvodić D, Matković-Jožin S. Effect of long-term, low-dose clarithromycin on T helper 2 cytokines, eosinophilic cationic protein and the 'regulated on activation, normal T cell expressed and secreted' chemokine in the nasal secretions of patients with nasal polyposis. The Journal of laryngology and otology. 2012; 126(5):495-502.

23. Lund VJ, Kennedy DW. Staging for rhinosinusitis. Otolaryngol Head Neck Surg. 1997; 117(3 Pt 2):S35-40.

24. Liang KL, Jiang RS, Wang RC, et al. Upper airway inflammation exacerbates bronchial hyperreactivity in mouse models of rhinosinusitis and allergic asthma. Int Forum Allergy Rhinol. 2013; 3(7):532-542.

25. Al-Sayed AA, Agu RU, Massoud E. Models for the study of nasal and sinus physiology in health and disease: A review of the literature.Laryngoscope Investig Otolaryngol. 2017; 2(6):398-409.

26. Xiang R, Zhang QP, Zhang W, et al. Different effects of allergic rhinitis on nasal mucosa remodeling in chronic rhinosinusitis with and without nasal polyps. Eur Arch Otorhinolaryngol. 2019; 276(1):115-130.

27. Hellings PW, Fokkens WJ, Bachert C, et al. Positioning the principles of precision medicine in care pathways for allergic rhinitis and chronic rhinosinusitis - A EUFOREA-ARIA-EPOS-AIRWAYS ICP statement.Allergy. 2017; 72(9):1297-1305.

28. Shamji MH, Thomsen I, Layhadi JA, et al. Broad IgG repertoire in patients with chronic rhinosinusitis with nasal polyps regulates proinflammatory IgE responses. J Allergy Clin Immunol. 2019; 143(6):2086-2094 e2082.

29. Wallwork B, Coman W, Mackay-Sim A, Greiff L, Cervin A. A double-blind, randomized, placebocontrolled trial of macrolide in the treatment of chronic rhinosinusitis. Laryngoscope. 2006; 116(2):189-193.

30. Haxel BR, Clemens M, Karaiskaki N, Dippold U, Kettern L, Mann WJ. Controlled trial for long-term low-dose erythromycin after sinus surgery for chronic rhinosinusitis. Laryngoscope. 2015; 125(5):1048-1055. 
31. Wu SH, Hsu SH, Liang KL, Jiang RS. The effects of erythromycin towards the treatment of persistent rhinosinusitis after functional endoscopic sinus surgery: A randomized, active comparator-controlled study. J Chin Med Assoc. 2019; 82(4):322-327.

32. Soyka MB, Wawrzyniak P, Eiwegger T, et al. Defective epithelial barrier in chronic rhinosinusitis: the regulation of tight junctions by IFN-gamma and IL-4. J Allergy Clin Immunol . 2012; 130(5):1087-1096 e1010.

33. Miyagawa T, Fujita T, Yumoto H, et al. Azithromycin recovers reductions in barrier function in human gingival epithelial cells stimulated with tumor necrosis factor-alpha. Arch OralBiol. 2016; 62:64-69.

34. Gotfried MH. Macrolides for the treatment of chronic sinusitis, asthma, and COPD. Chest. 2004(2 Suppl); 125:52S-60S; quiz 60S-61S.

35. Sadamatsu H, Takahashi K, Tashiro H, et al. The non-antibiotic macrolide EM900 attenuates HDM and poly(I:C)-induced airway inflammation with inhibition of macrophages in a mouse model. Inflamm Res.2020; 69(1):139-151.

36. Pukhalsky AL, Shmarina GV, Kapranov NI, Kokarovtseva SN, Pukhalskaya D, Kashirskaja NJ. Antiinflammatory and immunomodulating effects of clarithromycin in patients with cystic fibrosis lung disease.Mediators Inflamm. 2004; 13(2):111-117.

37. Park SJ, Lee YC, Rhee YK, Lee HB. The effect of long-term treatment with erythromycin on Th1 and Th2 cytokines in diffuse panbronchiolitis.Biochem Biophys Res Commun. 2004; 324(1):114-117.

38. Huang Z, Zhou B. Clarithromycin for the treatment of adult chronic rhinosinusitis: a systematic review and meta-analysis. Int Forum Allergy Rhinol. 2019; 9(5):545-555.

\section{Figure legends}

FIG 1. Representative images showing histological features of nasal tissues of various groups. Control: without rhinosinusitis; CRSsAR: chronic rhinosinusitis without allergic rhinitis; CRSwAR: chronic rhinosinusitis with allergic rhinitis; T: turbinate; P: polyp; H\&E: hematoxylin and eosin staining; PAS: periodic acid-Schiff staining.

FIG 2. (A) Cytokines levels in tissue homogenates from nasal mucosa of study subjects. Control: without rhinosinusitis; CRSsAR: chronic rhinosinusitis without allergic rhinitis; CRSwAR: chronic rhinosinusitis with allergic rhinitis. (B) Comparison of the levels of protein expression among the three groups. (C) Representative samples of protein expressions of study subjects. ${ }^{*} \mathrm{P}<0.05$.

FIG 3. Immunoglobulin levels of experimental mice ( $\mathrm{N}=8$ to $25 /$ group). CRSsAR: chronic rhinosinusitis without allergic rhinitis; CRSwAR: chronic rhinosinusitis with allergic rhinitis; EM: erythromycin; Dex: dexamethasone. ${ }^{*} \mathrm{P}<0.05$.

FIG 4. Representative images showing histological features of nasal tissues in (A) chronic rhinosinusitis mice without allergic rhinitis and (B) chronic rhinosinusitis mice with allergic rhinitis. Control: without rhinosinusitis; CRSsAR: chronic rhinosinusitis without allergic rhinitis; CRSwAR: chronic rhinosinusitis with allergic rhinitis; EM: erythromycin; Dex: dexamethasone; H\&E: hematoxylin and eosin staining; PAS: periodic acid-Schiff staining.

FIG 5. Cytokine levels in tissue homogenates taken from nasal-associated lymphoid tissues in the experimental mice ( $\mathrm{N}=5$ to 7 /group). CRSsAR: chronic rhinosinusitis without allergic rhinitis; CRSwAR: chronic rhinosinusitis with allergic rhinitis; EM: erythromycin; Dex: dexamethasone. ${ }^{*} \mathrm{P}<0.05$.

FIG 6. (A) Relative protein expressions of MUC5AC, e-cadherin, and claudin in nasal mucosa of experimental mice ( $\mathrm{N}=12$ to 24 /group). (B) Representative results of western blotting. CRSsAR: chronic rhinosinusitis without allergic rhinitis; CRSwAR: chronic rhinosinusitis with allergic rhinitis; EM: erythromycin; Dex: dexamethasone. ${ }^{*} \mathrm{P}<0.05$. 


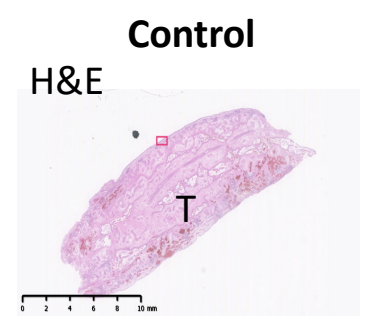

CRSsAR

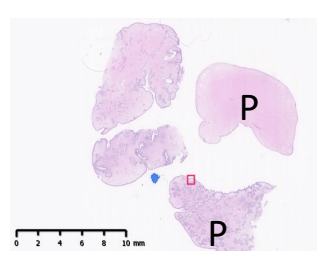

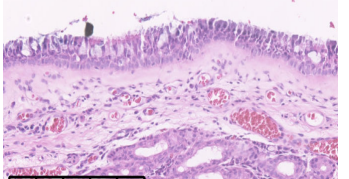

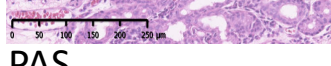

PAS

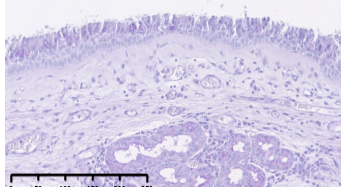

Claudin-1

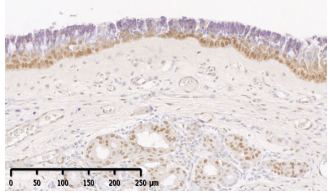

E-cadherin

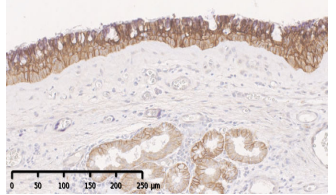

CRSwAR
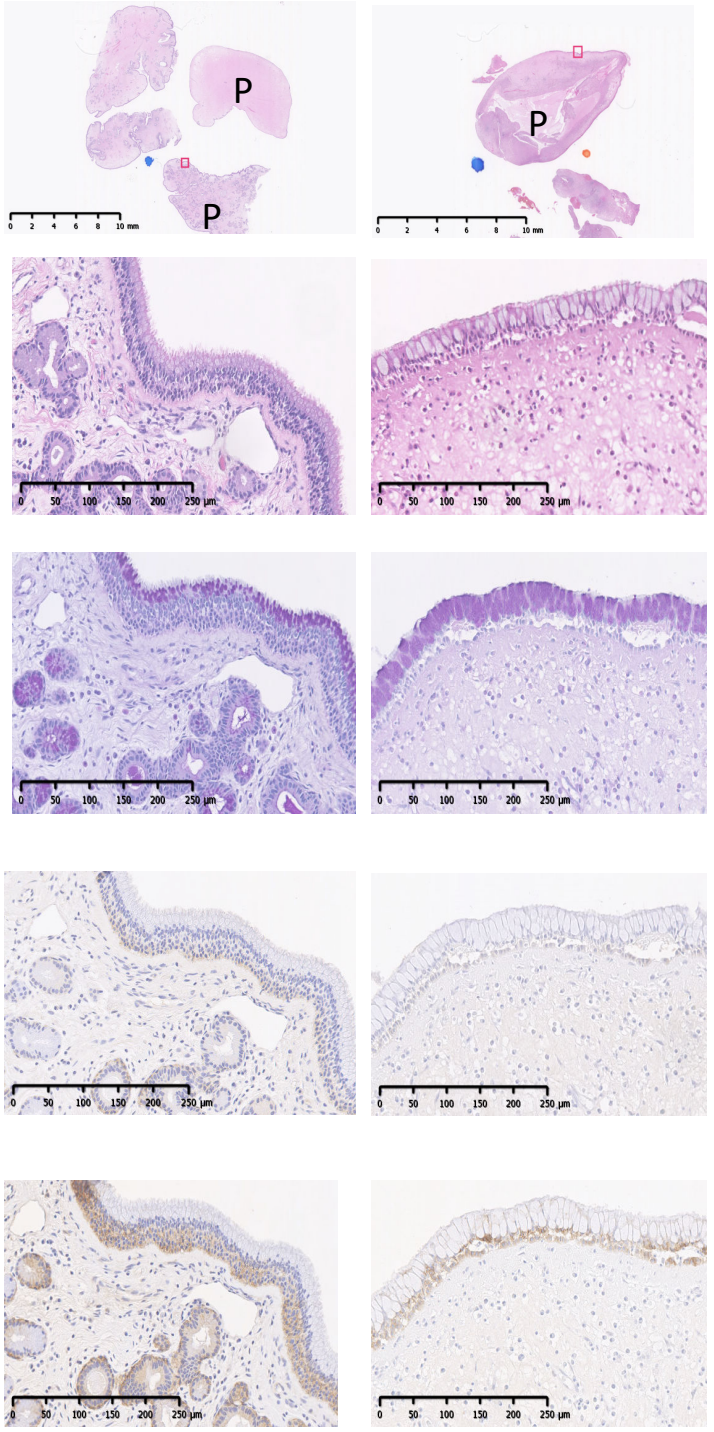
(A)
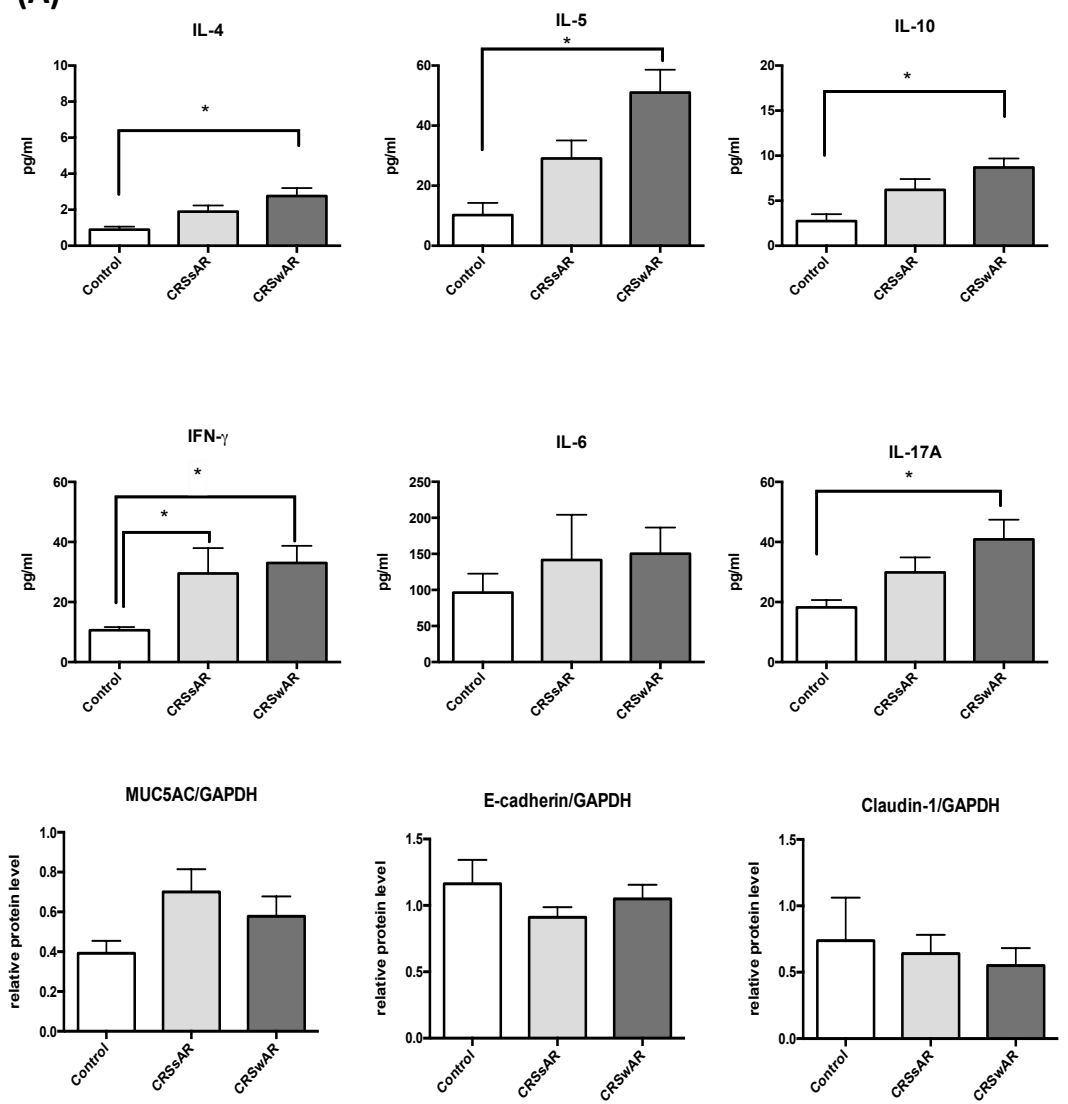

(C)

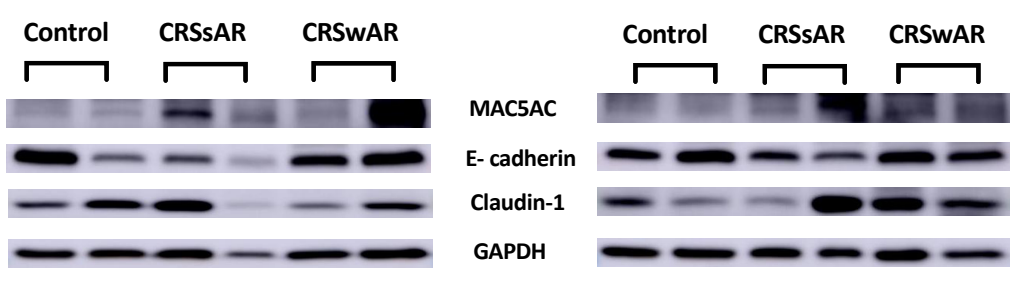



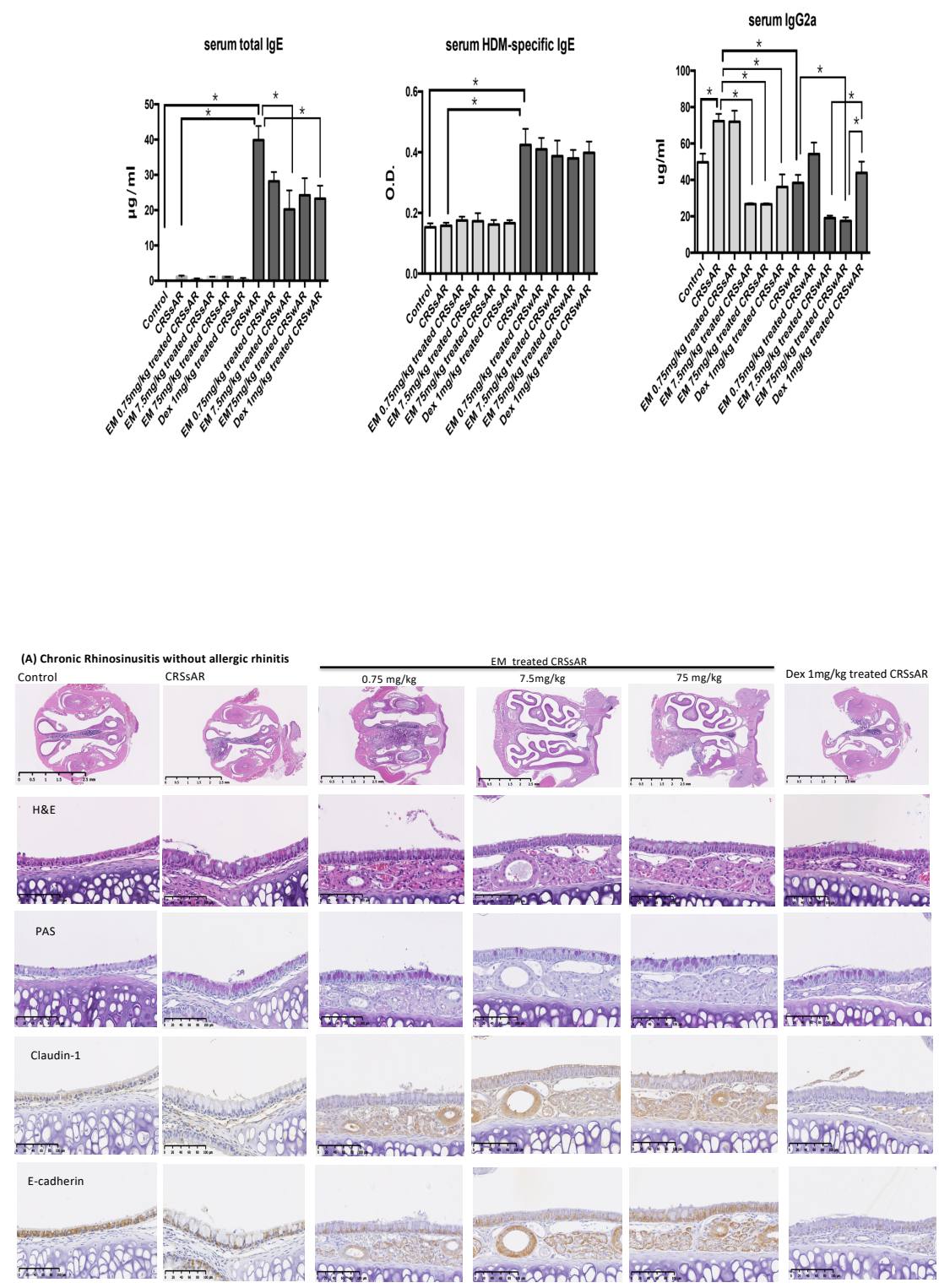

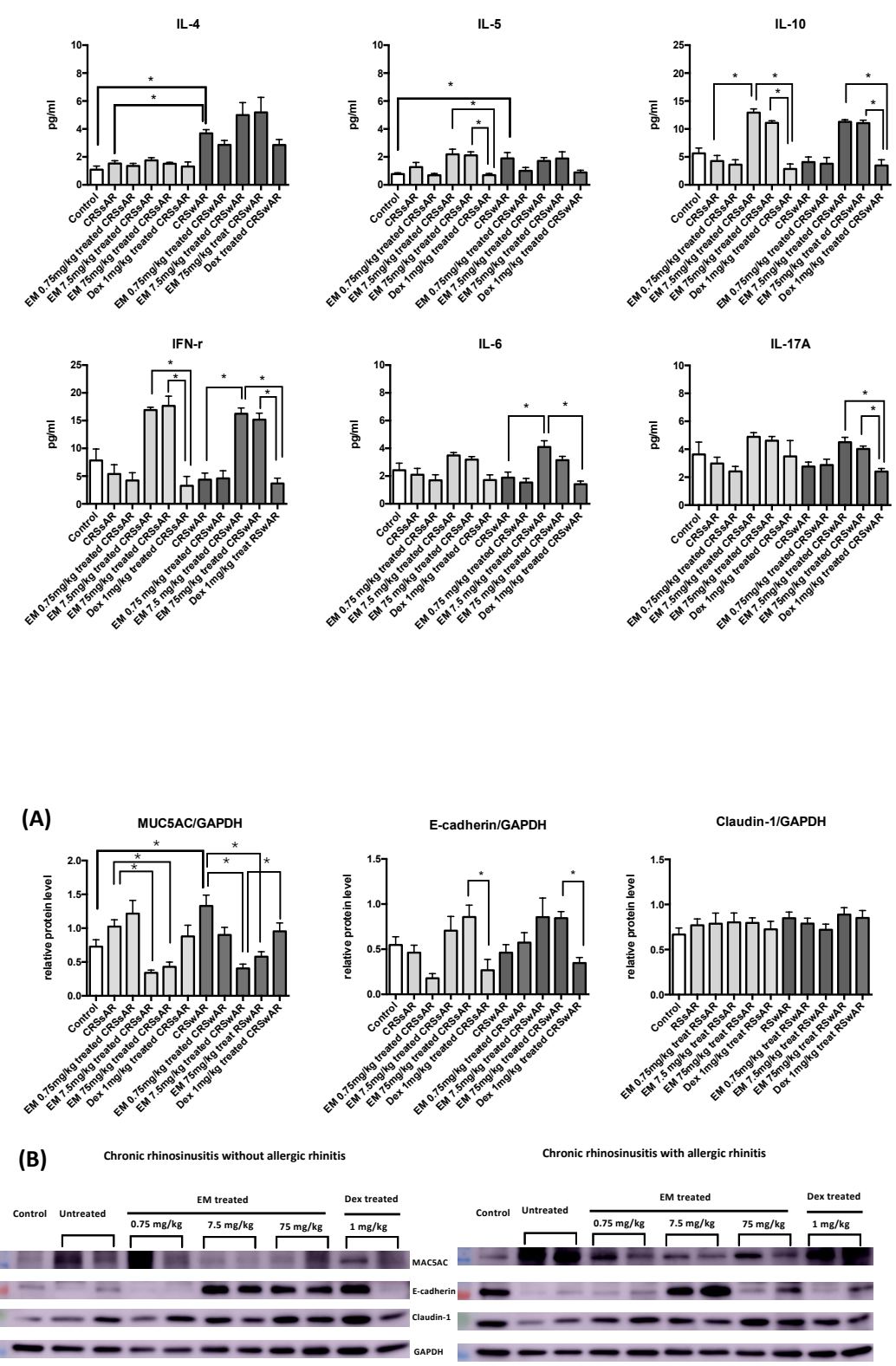